\title{
Religiosity, Family Orientation, and Life Satisfaction of Adolescents in Four Countries
}

\author{
Colette Sabatier', Boris Mayer ${ }^{2}$, Mihaela Friedllmeier ${ }^{3}$, \\ Katarzyna Lubiewska ${ }^{4}$, and Gisela Trommsdorff ${ }^{2}$
}

\begin{abstract}
This study examined the rarely investigated interplay between religiosity, family orientation, and life satisfaction of adolescents across four countries with a Christian tradition and different religious contexts. A mediation relationship between religiosity and life satisfaction through family orientation moderated by the country context of religiosity was examined. In a sample of I,077 adolescents from France $(n=172)$, Germany $(n=270)$, Poland $(n=348)$, and the United States $(n=287)$, we found that in all cultures, religiosity had a positive impact on adolescents' family orientation, which was in turn related to a higher life satisfaction. This link was stronger in cultures with a high overall religiosity (Poland and the United States) as compared to one of the two cultures with the lowest importance of religion (Germany).
\end{abstract}

\section{Keywords}

religion, life satisfaction, family orientation, adolescence

Adolescence is a period of an intense striving for meaning, ideological hunger, as well as a desire for autonomy and connectedness (Erikson, 1968; Good \& Willoughby, 2008). Family and religion are two social institutions that channel adolescents' quest for meaning and may impact their satisfaction with life. During this period, the link with the family, the primary social unit, has been shown to be of vital importance (e.g., Caprara, Pastorelli, Regalia, Scabini, \& Bandura, 2005). Religion, as a cultural system, provides a framework for social behavior, social norms, and sense of life (Geertz, 1973). It is seen as one of the resources for individual well-being (Ferriss, 2002), as well as an authority that sustains family values, roles, and cohesion (Chatters \& Taylor, 2005). The present study investigates the interplay between attitudes toward religiosity and family and the life satisfaction of adolescents across four countries.

The vast majority of studies on the psychology of religion focused on the link between religiosity and various facets of life such as well-being, values, and family relationships among adults

\footnotetext{
'Université Victor Segalen, Bordeaux, France

${ }^{2}$ University of Konstanz, Germany

${ }^{3}$ Grand Valley State University, Allendale, Michigan

${ }^{4}$ Kazimierz Wielki University in Bydgoszcz, Poland

Corresponding Author:

Colette Sabatier, Laboratoire de Psychologie EA 4I 39, Université Victor Segalen, 3 ter place de la Victoire, F33076 Bordeaux, Cedex France.

Email: Colette.Sabatier@u-bordeaux2.fr
} 
(Chatters \& Taylor, 2005; Hackney \& Sanders, 2003; Saroglou \& Munoz-Garcia, 2008). The function of religiosity appears to be complex, multifaceted, and context-related. Its influence seems to be positive on many dimensions of well-being, but is in most cases mediated through several components of life such as social support, marital relationship, optimism, or meaning of life (e.g., Cohen, 2002; Steger \& Frazier, 2005). Furthermore, religious denominations, religious national contexts, and country level of affluence appear to moderate these links (Cohen, 2002; Roccas \& Schwartz, 1997; Saroglou, Delpierre, \& Dernelle, 2004). For instance, religious people tend to be happier in religious nations (Okulicz-Kozaryn, 2010). The association between religiosity and values varies according to the church-state relationship (cordial vs. oppositional; see Roccas \& Schwartz, 1997) or the proportion of Protestants in the country (see Saroglou et al., 2004).

With regard to adolescent development, much of the research has been devoted to the analysis of the moral role of religiosity, and of the protective role against distress and risk behaviors (King \& Furrow, 2004; Wong, Rew, \& Slaikeu, 2006). Few studies have examined the influence of religiosity on life satisfaction, and little is known about how religiosity may shape adolescents' family orientation (Regnerus \& Burdette, 2006).

The aim of the current study is to fill this gap by investigating the role of adolescents' religiosity for their life satisfaction and for their family orientation across four national contexts (France, Germany, Poland, and United States). Drawing upon research with adults, we adopted a moderated mediation perspective. Considering the perceived importance of family by adolescents for their well-being and the interplay between religiosity and family life, we examine the role of adolescents' family orientation as a link between their religiosity and life satisfaction.

\section{Adolescents'Religiosity and Life Satisfaction}

Life satisfaction, or perceived quality of life, is a broad and complex construct, which encompasses an evaluation of the full range of overall functioning, and an appraisal of one's life in general and in specific domains, such as family, health, social support, and environment (Diener, Suh, Lucas, \& Smith, 1999; Huebner, 2004). Researchers have identified a large number of factors influencing adolescents' life satisfaction such as cultural and religious beliefs or family life (Casas, Figuer, Gonzalez, \& Malo, 2007; Proctor, Linley, \& Maltby, 2009).

Empirical research suggests that religiosity is positively associated with life satisfaction, but some inconsistent results are observed. An association between religiosity and life satisfaction was observed in studies of British adolescents (Francis, Jones, \& Wilcox, 2000), and of Spanish adolescents (Casas et al., 2007), but not of German adolescents (Francis, Ziebertz, \& Lewis, 2003). Furthermore, in a study with a multidenominational U.S. sample, no correlation has been observed between life satisfaction and both intrinsic and extrinsic religiosity. Nonetheless, in this latter study, indirect paths between religiosity and life satisfaction were found through the endorsement of existential beliefs (e.g., belief in afterlife or death anxiety; Cohen et al., 2005).

Among the explanations of such inconsistent results, two main arguments have been suggested: (a) the differential effects of country-specific religious cultural contexts (Lavric \& Flere, 2008) as well as (b) the possibility that other sources of influences may act as a link between religiosity and life satisfaction, questioning the direct influence of religiosity (King \& Furrow, 2004).

With regard to the first argument, the level of religiosity in the neighborhood and in peer networks may shape the importance of religious beliefs for the self (Barrett, Pearson, Muller, \& Frank, 2007). Religion may have a greater importance for well-being in contexts where there are few alternatives outside the parish community for community services such as nonexpensive leisure or family services than in contexts where the option for such services is unrelated to church affiliation (Agate, Zabriskie, \& Eggett, 2007; Regnerus, Smith, \& Smith, 2004). 
With regard to the second argument, a strong connection with the social environment based on social interaction, trust, and shared vision (e.g., the social capital as described by Bourdieu, 1980) has been identified as a mediating variable between religiosity and life satisfaction (King \& Furrow, 2004). The family orientation as expressed by the sense of connectedness and the value of mutual obligations within the family is a component of such social capital for adolescents (Valenzuela \& Dornbusch, 1994), which is crucial for their well-being and identity anchorage (Sweeting \& West, 1995). However, to our knowledge, no empirical research has addressed directly the question of family orientation as a mediator between religiosity and life satisfaction. Research has been much more interested in the familial transmission of religiosity than in the links between adolescent's religiosity and the endorsement of family orientation (e.g., Day et al., 2009).

\section{Family Orientation and Life satisfaction}

Family orientation has received a lot of attention from researchers with regard to its change over time and cross-cultural variations (Georgas, Berry, van de Vijver, Kagitçibasi, \& Poortinga, 2006). Family relationships are built on a number of intertwined but independent dimensions and forms of solidarities (Bengston \& Roberts, 1991).

Two dimensions appear as fundamental: (a) the family relationship value (see Georgas et al., 2006) and (b) the family interdependence (Cross, Bacon, \& Morris, 2000). The family relationship value considers the family as a social unit that provides a sense of in-group to which an individual may identify and where one may find support for one's well-being. Obligations between family members and the harmony within this social unit are valued. This represents a normative view of the family. Family interdependence is a form of interdependent self-construal. Self-construal is conceptualized as a constellation of thoughts, feelings, and actions concerning one's relationship to others (interdependent self-construal) and the self as distinct from others (independent self-construal) (Singelis, 1994). Distinct interdependent self-construals have been identified varying according to the group or social unit considered (Cross et al., 2000). Family interdependence stresses the importance of the relationships with the family for the self.

There is evidence that the value and the perception of connectedness with the family feeds the basic needs of adolescents and in turn sustains the well-being of adolescents, even in Western societies where individuation and autonomy are emphasized as a developmental task (Kagitçibasi, 2007; Pomerantz, Qin, Wang, \& Chen, 2009; Valenzuela \& Dornbusch, 1994).

\section{Religion and Family Orientation}

Religion is one of the several cultural systems that shape family values and encourage family orientation (Georgas et al., 2006). As cultural systems, religions provide many messages toward the family and inculcate an ethos of and within the family (Chatters \& Taylor, 2005). Religious content, meaning, myths, and behaviors are important in defining family values, roles, identities, and self-construals. For instance, many passages of the Bible and New Testament affirm and validate positive norms of filial obligations and assistance to family members. Major milestones of family life are commemorated in religious rituals and ceremonies, such as birth, marriage, and death. In the Christian tradition, the confirmation at adolescence is an occasion of specific religious teaching and of thinking about meaning of life (Chatters \& Taylor, 2005).

However, many of these messages and customs appear to be very similar to secular messages deep-rooted in the secular national cultures. Secular educational and psychological approaches as well as states and political ideologies are concerned with family life. They provide messages for healthy behaviors related to parental and marital relationships, as well as for familial sense of connectedness and family solidarity (Agate et al., 2007; Berne \& Huberman, 2000; Mahoney, 2005; 
Revillard, 2007). Families, nonreligious and religious, socialize their adolescents in order to provide them a sense of connectedness and the value of mutual obligations with many nonreligious daily activities, practices, and discourses (Agate et al., 2007; Vedder, Berry, Sabatier, \& Sam, 2009).

Although there are no empirical studies with adolescents directly investigating the influence of religiosity on family orientation, some studies suggest that religiosity promotes strong familial ties as perceived by adolescents, which in turn sustains life satisfaction (Agate et al., 2007; Snider, Clements, \& Vazsonyi, 2004). This association between religiosity and adolescent's family orientation may be strengthened in religious national contexts where religion and family are tightly linked institutions in comparison to countries where this is not the case.

\section{Country Context of Religiosity}

The four countries in this study - France, Germany, Poland, and the United States - have in common a Christian historical background, a democratic political system, the guarantee by law of the freedom of conscience and faith, and no official religion (see "Eurel," 2010). According to the Human Development Index (HDI, Human Development Report, 2009), they all benefit from a high quality of life. France, Germany, and the United States are ranked among the 22 highest out of 182 countries. The quality of life in Poland is lower but nonetheless high (HDI = .88 ; rank $=41$ ). However, these countries differ on many aspects with regard to their religious contexts: the percentage of believers, diversity of denomination, importance of religious beliefs, and church-state relationship.

With regard to the percentage of believers and the diversity of faith (see "Eurel," 2010, for information in Europe, and Pew Research Center for United States), France is a country of Catholic culture (51\% of the population) with a very high proportion of nonbelievers ( $42 \%)$; Germany has three main denominational groups in about equal parts—Protestant (31\%), Catholic (33\%), and nonbelievers (29\%); Poland is mainly Catholic (90\%); and in the United States, the proportion of believers is high with a mosaic of denominations, among them different Protestant denominations (51\%, altogether), Catholics $(24 \%)$, and unaffiliated, including nonbelievers (16\%). According to "Pew reports," the percentage of adults for whom religion is "very important" is $11 \%$ in France, $21 \%$ in Germany, 36\% in Poland, and 59\% in the United States (Pew Research Center, 2002). Both the United States and Poland appear to have an exceptionally high level of religiosity compared to similar countries. The title of the "Pew report" is unequivocal: "Among wealthy nations US stands alone in its embrace of religion" (Pew Research Center, 2002). Poland is one of the few Eastern European countries having resisted to the communist enculturation/indoctrination toward non-religiosity, and it is known for its strong historical emphasis on religion compared to other Eastern European countries (Boski, 2009; Cieciuch, 2007). In contrast, France and Germany have long traditions of church-state separation since the early beginning of the 20 th century.

\section{Research Goals}

The aim of the current study is to examine the relationship between adolescents' subjective religiosity and their life satisfaction across four countries. It attempts to fill a gap in the literature by paying attention to family orientation as a mediator between religiosity and life satisfaction. The four cultures offer the possibility to examine the moderating role of cultural and religious national context for the association between religiosity, family orientation, and life satisfaction.

We hypothesize the following: 
(1) There are positive relationships between the subjective religiosity and the life satisfaction of adolescents;

(2) there are positive relationships between the subjective religiosity and adolescents' family orientation;

(3) these two relationships vary across countries: in countries with a secular tradition such as France and Germany, both relationships are lower than in the other countries;

(4) the link from subjective religiosity to life satisfaction is mediated by adolescents' family orientation;

(5) this mediation pathway will be observed in all four countries, but because national context moderates the first two links, this may be stronger in cultural contexts where the importance of religion is emphasized.

\section{Method}

\section{Sample}

The sample was drawn out from four national samples of the Value of Children international research, a three-generation study involving adolescents, mothers, and maternal grandmothers (Trommsdorff \& Nauck, 2005). Families have been individually contacted first through one of the three members, and thereafter, the project was presented to each member who participated on a voluntary basis. All families lived in urban or suburban areas. In France, they have been recruited in different parts of the country through graduate students' networks (former school, relative networks, work, etc.). In Germany, they had been recruited through residents' registration offices. They lived in three locations in about equal proportions: Chemnitz (a middle-sized town in Eastern Germany), Konstanz (a middle-sized town in Southern Germany), and Essen (a larger city from an urbanized industrialized area in Northwestern Germany). In Poland, they lived in different parts of the country. In the United States, they have been recruited mostly through school, but also through various clubs (church, sport, YMCA) and graduate students' networks. They all lived in Michigan, a state where the degree of religiosity is at the national mean level.

For the current study, only the adolescent participants were selected. They were asked a wide range of questions on values, family relationships, and well-being in a questionnaire filled in at home. Adolescents' religious affiliation was assessed by providing a list of religious denominations and beliefs (including various forms of nonreligious convictions such as agnosticism, atheism, or no belief at all). Since the great majority of adolescents either indicated a Catholic or Protestant Christian denomination or one of the nonreligious categories, we discarded all small groups of minority religions (such as those with Muslim faith) in order to avoid unwanted heterogeneity due to minority (religious) cultures.

Overall, the sample consisted of 1,077 adolescents ( $60 \%$ female) with a mean age of 15.76 years $(S D=1.21$; range $=13-18)$. The French sample included 172 adolescents $(55 \%$ female; $59 \%$ Catholic and $41 \%$ nonreligious); the German sample included 270 adolescents (56\% females; 28\% Catholic, 23\% Protestant, and 49\% nonreligious); the Polish sample included 348 adolescents (61\% female; 95\% Catholic and 5\% nonreligious); and the American sample included 287 adolescents ( $66 \%$ female; $21 \%$ Catholic, $67 \%$ Protestant, and $12 \%$ nonreligious).

\section{Measures}

For all measures, adolescents indicated on a 5-point Likert-type scale their agreement with the statements or the importance of the respective value $(1=$ strongly disagree or not important at all; 5 = strongly agree or very important). 
Religiosity or importance of religion was measured by one question following the question on religious affiliation: "How important is this belief for you?" Nonreligious adolescents who did not indicate the importance of their "nonbelief" were given a value of 1 (not important at all) a posteriori.

Life satisfaction was measured by five questions assessing the general aspect (free of context) of satisfaction with life and the satisfaction in specific domains. The general life satisfaction was measured by one item from the Satisfaction With Life Scale (e.g., Diener, Gohm, Suh, \& Oishi, 2000): "All things considered, how satisfied are you with life as a whole these days?" The four items referring to specific aspects of life (friendships, health, school, and family) came from Henrich and Herschbach's (1995) instrument. Cronbach's alphas were satisfactory with .67, .72, .75 , and .72 for France, Germany, Poland, and the United States, respectively.

Family orientation was measured through two scales. The first scale named family relationship values included five items from the Relations with Family and Kin scale by Georgas et al. (2006). These questions form a single dimension of questions about harmony within the family (e.g., "One should maintain good relationships with one's relatives") and children's obligations toward parents and other family members (e.g., "Children have an obligation to care for their parents when their parents are old"). The second scale named family interdependence was measured by five questions, with the highest factor loadings on the interdependence factor of Singelis's (1994) original instrument measuring self-construals. While in the original instrument interdependence refers unspecifically to "people around me" or "my group," in this study, the item-focus was changed to the family (e.g., "I often have the feeling that my relation with my family is more important than my own accomplishments"). Both scales are representing the wider construct of Family Orientation in our study. Alphas were satisfactory, with $.81, .76, .84$, and .83 for France, Germany, Poland, and the United States, respectively.

\section{Statistical Analysis}

Applying the program AMOS 18.0 we used multigroup structural equation modeling to test our claim of moderated mediation. Bootstrapping (2000 bootstrap samples) was used to obtain significance tests (confidence intervals) of total and indirect effects. Adolescents' gender and age were included as control variables. Since measurement error is supposed to be absent for the assessment of participants' gender and age, these control variables were included as observed variables in the model. Religiosity was included as a single indicator latent variable measured by our importance of religion item. We decided to fix the error variance of this indicator to .20 (for a discussion of this approach, see Hayduk, 1996).

We used item parceling to obtain observed indicators for the latent variables family orientation and life satisfaction using the "item-to-construct balance approach" (Little, Cunningham, Shahar, \& Widaman, 2002, p. 166). In this approach, first the unidimensionality of the underlying construct is confirmed, and then parcels are constructed according to the loadings of the items on the common factor. This is done by combining higher loading items with lower loading items to maximize the "balance" of the parcels in terms of homogeneous loadings on the latent construct. Furthermore, it is preferable to have a relatively low number of parcels and a relatively high number of items per parcel (Little et al., 2002). For family orientation, an exploratory pancultural principal component analysis (PCA) of the per country $z$ standardized variables combining the 10 items of the Family Relationship Values and the Family Interdependence scale yielded a clearly unidimensional solution, with all items loading $>.5$ on the common factor. Therefore, three parcels were created according to the item-to-construct balance approach (two parcels by averaging across three items, and one parcel with four items). Items in the respective parcels were mixed with regard to the two source scales. The pancultural PCA for life satisfaction confirmed the 


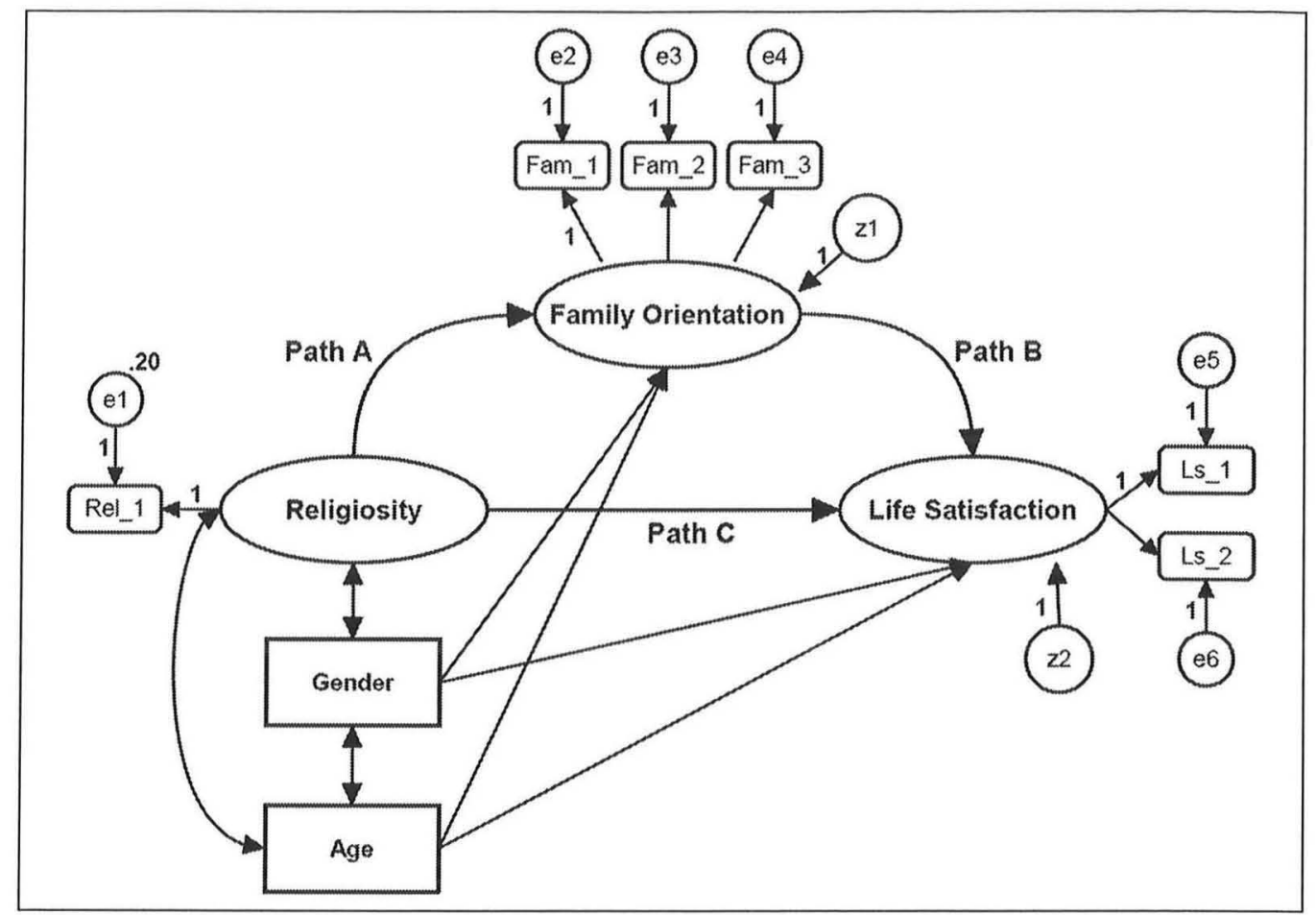

Figure I. Generic Mediation SEM Model Including Control Variables

unidimensionality of the construct with all items loading $>.6$ on the common factor. Therefore, two parcels (one with two, the other with three items) were constructed. Figure 1 summarizes the proposed SEM mediation model.

The multigroup analysis of moderated mediation proceeded in the following steps: First, we tested the cross-cultural equivalence of the measurement model (metric invariance). Second, we tested the cross-cultural equality of specific structural paths in our mediation model as reflected in the hypotheses. Finally, we checked the cross-cultural equivalence of the effects of control variables (gender and age) and of further hierarchical constraints (structural covariances, structural residuals, and measurement residuals).

\section{Results}

\section{Preliminary Analysis: Cross-Cultural Differences Regarding Adolescents' Religiosity}

Because adolescents' importance of religion is our variable representing the assumed differences in country-level religiosity, a preliminary ANOVA was carried out. The results showed a significant main effect of culture, $F(3,1073)=136.61, p<.001, \eta^{2}=.28$. Post hoc Scheffé comparisons revealed that U.S. $(M=3.80, S D=1.38)$ and Polish $(M=3.58, S D=1.01)$ adolescents reported a higher importance of religion than French $(M=2.23, S D=1.29)$ and German $(M=$ 2.05, $S D=1.28$ ) adolescents. U.S. and Polish as well as French and German adolescents did not differ significantly from each other, respectively. 


\section{Moderated Mediation: Multigroup Structural Equation Modeling}

We start with a series of SEM models with varying equality constraints across cultures to test cross-cultural differences and similarities with respect to the model parameters. Most importantly, models testing the cross-cultural equality of Paths A, B, and C of the mediation model are carried out to test Hypothesis 3 of weaker effects in the low-religiosity cultures of France and Germany as compared to the high-religiosity cultures of Poland and the United States.

Model fit and model comparisons. The results of the unconstrained base model showed a significant $\chi^{2}$, indicating a nonfitting model (see Table 1). However, all other indicators of model fit were excellent, including a relatively low ratio of $\chi^{2}$ to degrees of freedom. Since the overall $\chi^{2}$ is known to be sensitive to sample size (van den Vijver \& Leung, 1997), we concluded that the unconstrained mediation adequately fits our data. In the following model, we constrained the measurement weights of the latent variables family orientation and life satisfaction to be equal across cultures to test the cross-cultural metric invariance of the measurement model (Model 1). Since the $\chi^{2}$ difference test of this model compared to the unconstrained model was nonsignificant $\left(\Delta \chi^{2}=8.13, \Delta d f=9, p=.52\right)$, the measurement model showed metric or construct equivalence across the four cultural groups (see Table 1). Additionally, this model yielded a considerably lower information criterion AIC (Akaike, 1987) than the unconstrained model, indicating that it should be preferred over the latter when parsimony is considered in addition to model fit.

Models 2.1 to 2.5 test the cross-cultural equality of specific structural paths in the mediation model. In the first of these models (Model 2.1), Path A, the path from religiosity to family orientation was restricted to be equal across the four cultural groups. When this model was compared to the metric invariance model (Model 1), a significant $\chi^{2}$ difference resulted $\left(\Delta \chi^{2}=10.56, \Delta d f=\right.$ $3, p<.05$ ), indicating that the four countries differed with respect to the effect of religiosity on family orientation. To probe this difference, we computed Models 2.1.1 to 2.1.6 where Path A equality constraints were imposed for two cultural groups in each model, respectively. Thus, Model 2.1.1 compared French and German adolescents with regard to the effect of religiosity on family orientation, whereas Model 2.1.2 compared French and Polish adolescents, and so on (see Table 1). The resulting $\chi^{2} \mathrm{~s}$ of these "post-hoc comparison" models were again compared to the metric invariance model (Model 1) via $\chi^{2}$ difference tests. The results showed that French and German adolescents did not differ significantly from each other $\left(\Delta \chi^{2}=2.84, \Delta d f=1, p=.09\right)$, as well as French and Polish adolescents $\left(\Delta \chi^{2}=1.07, \Delta d f=1, p=.30\right)$ and French and U.S. adolescents $\left(\Delta \chi^{2}=0.00, \Delta d f=1, p=.95\right)$. A further nonsignificant difference resulted for the comparison of Polish and U.S. adolescents $\left(\Delta \chi^{2}=1.61, \Delta d f=1, p=.21\right)$. Significant differences resulted for the comparisons of German and Polish adolescents $\left(\Delta \chi^{2}=9.67, \Delta d f=1, p<.01\right)$ as well as for German and U.S. adolescents $\left(\Delta \chi^{2}=3.92, \Delta d f=1, p<.05\right)$. In both instances, a weaker effect of religiosity on family orientation was found for German adolescents as compared to Polish and U.S. adolescents, respectively (see below).

In the next model (Model 2.2), cross-cultural differences with respect to the effect of family orientation on life satisfaction were tested by imposing equality constraints on Path B. Since the $\chi^{2}$ difference to Model 1 was nonsignificant $\left(\Delta \chi^{2}=0.99, \Delta d f=3, p=.80\right)$, the four cultures did not differ with regard to this effect. Model 2.3 imposed equality constraints on Path $\mathrm{C}$ representing the effect of religiosity on life satisfaction. The $\chi^{2}$ difference test comparing this model to Model 1 was also nonsignificant $\left(\Delta \chi^{2}=3.18, \Delta d f=3, p=.37\right)$, indicating that adolescents from the four cultural groups did not differ with regard to this effect.

Models 2.4 and 2.5 assessed the cross-cultural equivalence of the effects of the control variables gender and age on the latent variables family orientation and life satisfaction. Both models yielded nonsignificant $\chi^{2}$ difference tests in comparison to the metric invariance model $\left(\Delta \chi^{2}=\right.$ $1.48, \Delta d f=6, p=.96$ and $\Delta \chi^{2}=11.68, \Delta d f=6, p=.07$, respectively). Thus, the respective effects 
Table I. Model Fit Indices for the Base SEM and Models I Through 5 for the Multigroup Mediation Model

\begin{tabular}{|c|c|c|c|c|c|c|c|c|c|}
\hline Models & $d f$ & $\chi^{2}$ & $\chi^{2} / d f$ & $\mathrm{CFI}$ & TLI & RMSEA & AIC & $\Delta \chi^{2}$ & $\Delta d f$ \\
\hline Base SEM (unconstrained) & 52 & $92.53^{* * *}$ & 1.779 & .980 & .957 & .027 & 276.53 & - & - \\
\hline Model I: Measurement weights & 61 & $100.66 * *$ & 1.650 & .980 & .964 & .025 & 266.66 & 8.13 & 9 \\
\hline Model 2. I: Structural weights-Path A & 64 & $111.23^{* 20 *}$ & 1.738 & .976 & .959 & .026 & 271.23 & $10.57^{*}$ & 3 \\
\hline Model 2. I. I: Path A-France vs. Germany & 62 & $103.50 * *$ & 1.670 & .979 & .963 & .025 & 267.50 & $2.84+$ & I \\
\hline Model 2. I.2: Path A-France vs. Poland & 62 & $101.73 * *$ & 1.641 & .980 & .964 & .024 & 265.73 & 1.07 & I \\
\hline Model 2.1.3: Path A-France vs. US & 62 & $100.66 * *$ & 1.624 & .981 & .965 & .024 & 264.66 & 0.00 & I \\
\hline Model 2. I.4: Path A-Germany vs. Poland & 62 & $110.33^{* * *}$ & 1.780 & .976 & .957 & .027 & 274.33 & $9.67 * * *$ & I \\
\hline Model 2.1.5: Path A-Germany vs. US & 62 & $104.58 * *$ & 1.687 & .979 & .962 & .025 & 268.58 & $3.92^{*}$ & I \\
\hline Model 2. 1.6: Path A-Poland vs. US & 62 & $102.27 * *$ & 1.650 & .980 & .964 & .025 & 266.27 & 1.61 & 1 \\
\hline Model 2.2: Structural weights Path B & 64 & $101.65 \%$ & 1.588 & .981 & .967 & .023 & 261.65 & 0.99 & 3 \\
\hline Model 2.3: Structural weights Path C & 64 & $103.84^{* *}$ & 1.623 & .980 & .965 & .024 & 263.84 & 3.18 & 3 \\
\hline Model 2.4: Structural weights Gender & 67 & $102.14 * *$ & 1.524 & .982 & .971 & .022 & 256.14 & 1.48 & 6 \\
\hline Model 2.5: Structural weights Age & 67 & $112.34 * * *$ & 1.677 & .977 & .962 & .025 & 266.33 & 11.68 & 6 \\
\hline Model 2.6: Structural weights except Path A & 79 & $|18.8| * *$ & 1.504 & .980 & .972 & .022 & 248.81 & 18.15 & 18 \\
\hline Model 3: Model 2.6 + Structural covariances & 97 & $179.89 * *$ & 1.855 & .959 & .952 & .028 & 273.89 & $61.08 * \% *$ & 18 \\
\hline Model 4: Model 3 + Structural residuals & 103 & $200.90 * * *$ & 1.950 & .951 & .947 & .030 & 282.90 & $82.08 * \%$ & 24 \\
\hline Model 5: Model $4+$ Measurement residuals & 118 & $252.30 * * * *$ & 2.138 & .933 & .937 & .033 & 304.30 & $133.49 * * *$ & 39 \\
\hline Uncorrelated variables model & 112 & $2,119.65 * * *$ & 18.925 & .000 & .000 & .129 & 2183.65 & - & - \\
\hline
\end{tabular}

$+p<.10 . * p<.05 . * * p<.01 . * * * x<.001$. 
of both control variables on the mediating and the dependent variable did not differ across cultural groups.

In the previous models, distinct equality constraints were set for each of the three structural paths of the mediation model (Paths A, B, and C in Models 2.1, 2.2, and 2.3, respectively) as well as for the effects (structural paths) of the two control variables on the two latent variables (Models 2.4 and 2.5). Of all models that were compared to the metric invariance model, only Model 2.1 (constraining Path A to equality across cultures) was significantly different from Model 1. Therefore, in the following Model 2.6, all structural paths (including those of the control variables) except Path A were constrained to be equal across cultural groups. The comparison with Model 1 yielded a nonsignificant $\chi^{2}$ difference test $\left(\Delta \chi^{2}=18.15, \Delta d f=18, p=.45\right)$. Also, this model showed the lowest AIC of all models, and all other indicators of model fit (CFI, TLI, RMSEA) were very good (see Table 1).

Subsequent to the cross-cultural invariance tests with regard to structural paths, we imposed further equality constraints: In Model 3, structural covariances were set equal across cultures. This model yielded a significant $\chi^{2}$ difference to Model $2.6\left(\Delta \chi^{2}=61.08, \Delta d f=18, p<.001\right)$, indicating that, overall, the structural covariances among and the variances of the independent variable religiosity and both control variables were not equal across cultures. Model 4 additionally constrained the structural residuals (i.e., the residual variance of the latent variables family orientation and life satisfaction), and Model 5 in turn constrained the measurement residuals (i.e., the error variances of the observed indicators) to be equal across cultural groups. Both models yielded significant $\chi^{2}$ differences when compared to Model $2.6\left(\Delta \chi^{2}=82.08, \Delta d f=24, p<\right.$ .001 and $\Delta \chi^{2}=133.49, \Delta d f=39, p<.001$, respectively). In all three models (Models 3, 4, and 5), the AIC was higher than in Model 2.6. Thus, structural covariances, structural residuals, and measurement residuals were not invariant across cultural groups, and we can conclude that Model 2.6 is the most adequate model. Therefore, in addition to metric invariance, of all structural paths (including those of control variables), only the path from religiosity to family orientation (Path A) differed across cultural groups, and this difference was in turn only significant for the comparison of German versus Polish as well as German versus U.S. adolescents.

In the next section, we test the hypotheses regarding the effects of the mediation model (Hypotheses 1, 2, and 4). First, the estimates of the specific effects of the mediation model (Paths A, B, and C) are reported for each culture. Then, indirect and total effects are reported.

Model effects in four cultures. In the following, we report the parameter estimates of the unconstrained models for each of the four cultural groups. In all cultures, the effects of religiosity on family orientation (Path A) and of family orientation on life satisfaction (Path B) were positively significant. Furthermore, in all cultures, the effect of religiosity on life satisfaction (Path C) was nonsignificant. In Tables $2 \mathrm{a}$ and $2 \mathrm{~b}$, the parameter estimates are reported, and Figures $2 \mathrm{a}$ and $2 \mathrm{~b}$ summarize the results.

For the control variables, few and very inconsistent significant effects resulted in the four cultural groups. In France, the effect of age on family orientation was significant, indicating that older adolescents reported a slightly lower family orientation (see Table 2a). In Germany, a significant negative covariance between age and religiosity resulted, signifying that older adolescents were less religious than younger adolescents (see Table 2a). In Poland, a significant positive covariance of gender and religiosity occurred, indicating that girls were somewhat more religious than boys (see Table 2b). Finally, in the United States, a negative significant effect of age on life satisfaction resulted, demonstrating that older adolescent were less satisfied with their lives than younger adolescents (see Table $2 \mathrm{~b}$ ).

Indirect and total effects. For the purpose of testing mediation, it is of interest to assess the mediated (indirect) effect and the overall (total) effect of religiosity on life satisfaction in the four cultural groups. The total effect reflects the combined effect of the indirect effect (Path A $\times$ Path 
Table 2a. Parameter Estimates for the Unconstrained Base Model $(n=1077)$ : France and Germany

\begin{tabular}{|c|c|c|c|c|c|c|}
\hline & \multicolumn{3}{|c|}{ France $(n=172)$} & \multicolumn{3}{|c|}{ Germany $(n=270)$} \\
\hline & Estimate & SE & Standardized & Estimate & $S E$ & Standardized \\
\hline \multicolumn{7}{|l|}{ Paths } \\
\hline (A) REL $\rightarrow$ FAM & $.16 * * *$ & .04 & .36 & $.08 * * *$ & .02 & .25 \\
\hline (B) FAM $\rightarrow$ LS & $.41 * * *$ & .08 & .54 & $.58 * * *$ & .11 & .46 \\
\hline (C) REL $\rightarrow$ LS & .02 & .03 & .05 & -.03 & .03 & -.07 \\
\hline Gender $\rightarrow$ FAM & .08 & .08 & .08 & .08 & .05 & .10 \\
\hline Gender $\rightarrow$ LS & -.04 & .07 & -.05 & -.07 & .07 & -.07 \\
\hline Age $\rightarrow$ FAM & $-.09 *$ & .04 & -.19 & -.03 & .03 & -.08 \\
\hline Age $\rightarrow$ LS & -.05 & .03 & -.13 & .01 & .03 & .02 \\
\hline REL $\rightarrow$ Rel_la & 1 & & .94 & I & & .94 \\
\hline FAM $\rightarrow$ Fam_l ${ }^{\mathrm{a}}$ & 1 & & .88 & I & & .79 \\
\hline FAM $\rightarrow$ Fam_2 & $.99 * * *$ & 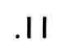 & .70 & $1.10 * * *$ & .11 & .74 \\
\hline FAM $\rightarrow$ Fam_3 & $1.04 * * *$ & .11 & .73 & $1.08 * * *$ & .10 & .74 \\
\hline $\mathrm{LS} \rightarrow$ Ls_I ${ }^{\mathrm{a}}$ & 1 & & .79 & I & & .80 \\
\hline LS $\rightarrow$ Ls_2 & 1.21 **** & .23 & .66 & 1.06 **** & .20 & .72 \\
\hline \multicolumn{7}{|l|}{ Covariances } \\
\hline REL $\leftrightarrow$ Gender & -.06 & .05 & -.10 & .01 & .04 & .02 \\
\hline REL $\leftrightarrow$ Age & .09 & .11 & .06 & $-.23 * *$ & .08 & -.18 \\
\hline Gender $\leftrightarrow$ Age & -.07 & .05 & -.11 & .05 & .03 & .09 \\
\hline \multicolumn{7}{|l|}{ Variances } \\
\hline REL & $1.44^{* * * *}$ & .18 & & $1.43^{* * *}$ & .14 & \\
\hline Gender & $.25^{* * *}$ & .03 & & $.25 * * *$ & .02 & \\
\hline Age & $1.38^{* * *}$ & .15 & & $1.12^{* * *}$ & .10 & \\
\hline zl & $.24 * * *$ & .04 & & $.13^{* * * *}$ & .02 & \\
\hline$z 2$ & $.11 * * *$ & .03 & & $.19 * * *$ & .04 & \\
\hline $\mathrm{el}^{\mathrm{a}}$ & .20 & & & .20 & & \\
\hline e2 & $.26 * * *$ & .04 & & $.15 * * *$ & .02 & \\
\hline e3 & $.30 * * *$ & .04 & & $.15 * * *$ & .02 & \\
\hline e4 & $.08^{* * *}$ & .02 & & $.09 * * *$ & .01 & \\
\hline e5 & $.31 * * *$ & .05 & & $.24 * * *$ & .05 & \\
\hline e6 & $.10^{* *}$ & .03 & & $.13^{* *}$ & .04 & \\
\hline
\end{tabular}

Note. REL = Religiosity; FAM = Family Orientation; LS = Life Satisfaction.

a.Value set a priori.

$+p<.10 . * p<.05 . * * p<.01 .{ }^{* * * *} p<.001$.

B) and the direct effect (Path C). It is comparable to the effect of the independent variable on the dependent variable in a model where the mediator variable is not included. Kenny (2009) suggests to test mediation in latent variable SEM models by comparing the total and the direct effect (Paths C and C' in Baron and Kenny's, 1986, classic terminology).

The standardized effects together with their bias-corrected $95 \%$ confidence intervals (CIs) are reported. In France, there was a significant indirect effect of $.20(S E=.06, p<.001,95 \%$ CI [.09, $.34])$, and a significant total effect of $.25(S E=.10, p<.05,95 \%$ CI $[.04, .44])$. In Germany, there was a significant indirect effect of .12 ( $S E=.04, p<.001,95 \%$ CI $[.05, .21])$, but a nonsignificant total effect of $.05(S E=.09, p=.57,95 \%$ CI $[-.12, .23])$. In Poland, there was a significant indirect effect of $.20(S E=.04, p<.001,95 \%$ CI $[.12, .29])$ and a significant total effect of .24 
Table 2b. Parameter Estimates for the Unconstrained Base Model $(n=1,077)$ : Poland and the United States

\begin{tabular}{|c|c|c|c|c|c|c|}
\hline & \multicolumn{3}{|c|}{ Poland $(n=348)$} & \multicolumn{3}{|c|}{ United States $(n=287)$} \\
\hline & Estimate & $S E$ & Standardized & Estimate & $S E$ & Standardized \\
\hline \multicolumn{7}{|l|}{ Paths } \\
\hline (A) REL $\rightarrow$ FAM & $.22^{\text {**** }}$ & .03 & .39 & $.16^{* * * *}$ & .03 & .38 \\
\hline (B) FAM $\rightarrow$ LS & $.43 * * *$ & .07 & .50 & $.54^{* * * *}$ & .08 & .49 \\
\hline (C) REL $\rightarrow$ LS & .02 & .03 & .04 & .04 & .03 & .09 \\
\hline Gender $\rightarrow$ FAM & $.11+$ & .06 & .10 & .01 & .07 & .01 \\
\hline Gender $\rightarrow$ LS & -.05 & .06 & -.05 & -.03 & .07 & -.03 \\
\hline Age $\rightarrow$ FAM & -.01 & .03 & -.03 & .00 & .02 & .00 \\
\hline Age $\rightarrow$ LS & -.02 & .02 & -.04 & $-.10 * * *$ & .02 & -.24 \\
\hline REL $\rightarrow$ Rel_la & I & & .91 & 1 & & .95 \\
\hline FAM $\rightarrow$ Fam_l $I^{\mathrm{a}}$ & I & & .88 & 1 & & .85 \\
\hline FAM $\rightarrow$ Fam_2 & $.96 * * *$ & .07 & .75 & 1.06 & .08 & .80 \\
\hline FAM $\rightarrow$ Fam_3 & $.93 * * *$ & .06 & .79 & .96 & .07 & .75 \\
\hline $\mathrm{LS} \rightarrow \mathrm{Ls} \_\mathrm{I}^{\mathrm{a}}$ & 1 & & .78 & 1 & & .92 \\
\hline LS $\rightarrow$ Ls_2 & $1.17^{* * * *}$ & .16 & .73 & .81 & .11 & .66 \\
\hline \multicolumn{7}{|l|}{ Covariances } \\
\hline REL $\leftrightarrow$ Gender & $.07 *$ & .03 & .14 & .05 & .04 & .08 \\
\hline REL $\leftrightarrow$ Age & -.09 & .07 & -.08 & .11 & .11 & .06 \\
\hline Gender $\leftrightarrow$ Age & -.01 & .03 & -.01 & -.01 & .04 & -.01 \\
\hline \multicolumn{7}{|l|}{ Variances } \\
\hline REL & $1.00^{* * * *}$ & .09 & & I.71**** & .16 & \\
\hline Gender & $.24^{* * * * *}$ & .02 & & $.22 * * *$ & .02 & \\
\hline Age & $1.37^{* * * k}$ & .10 & & $1.92^{* * * *}$ & .16 & \\
\hline zl & $.25 * * * *$ & .03 & & $.26 * * *$ & .03 & \\
\hline$z 2$ & $.17 * * *$ & .03 & & $.25 * * *$ & .05 & \\
\hline$e l^{a}$ & .20 & & & .20 & & \\
\hline e2 & $.15^{* * * *}$ & .02 & & $.22 * * *$ & .02 & \\
\hline e3 & $.22^{* * * *}$ & .02 & & $.20 * * *$ & .02 & \\
\hline e4 & $.09 * * * *$ & .02 & & .11 1*** & .02 & \\
\hline e5 & $.26 * * * *$ & .04 & & $.32 * * *$ & .04 & \\
\hline e6 & $.14 * * *$ & .03 & & .07 & .04 & \\
\hline
\end{tabular}

Note. REL = Religiosity; FAM = Family Orientation; $\mathrm{LS}=$ Life Satisfaction.

a.Value set a priori.

$+p<.10 *_{p}<.05 . *_{p}<.01 . * * * p<.001$.

$(S E=.07, p<.01,95 \% \mathrm{CI}[.09, .38])$. In the United States, there was a significant indirect effect of .18 $(S E=.04, p<.001,95 \% \mathrm{CI}[.11, .29])$ and a significant total effect of $.27(S E=.07, p<$ $.001,95 \%$ CI $[.13, .41])$. Since the direct effects (Path C) were all nonsignificant in France, Poland, and the United States and the respective total effects were significant, we can conclude that in these three cultures the overall effect of religiosity on life satisfaction was significantly mediated by adolescents' family orientation. In contrast, in Germany, we observe a significant indirect effect but not in the classical sense of mediation that would require a significant total effect in the first place. 


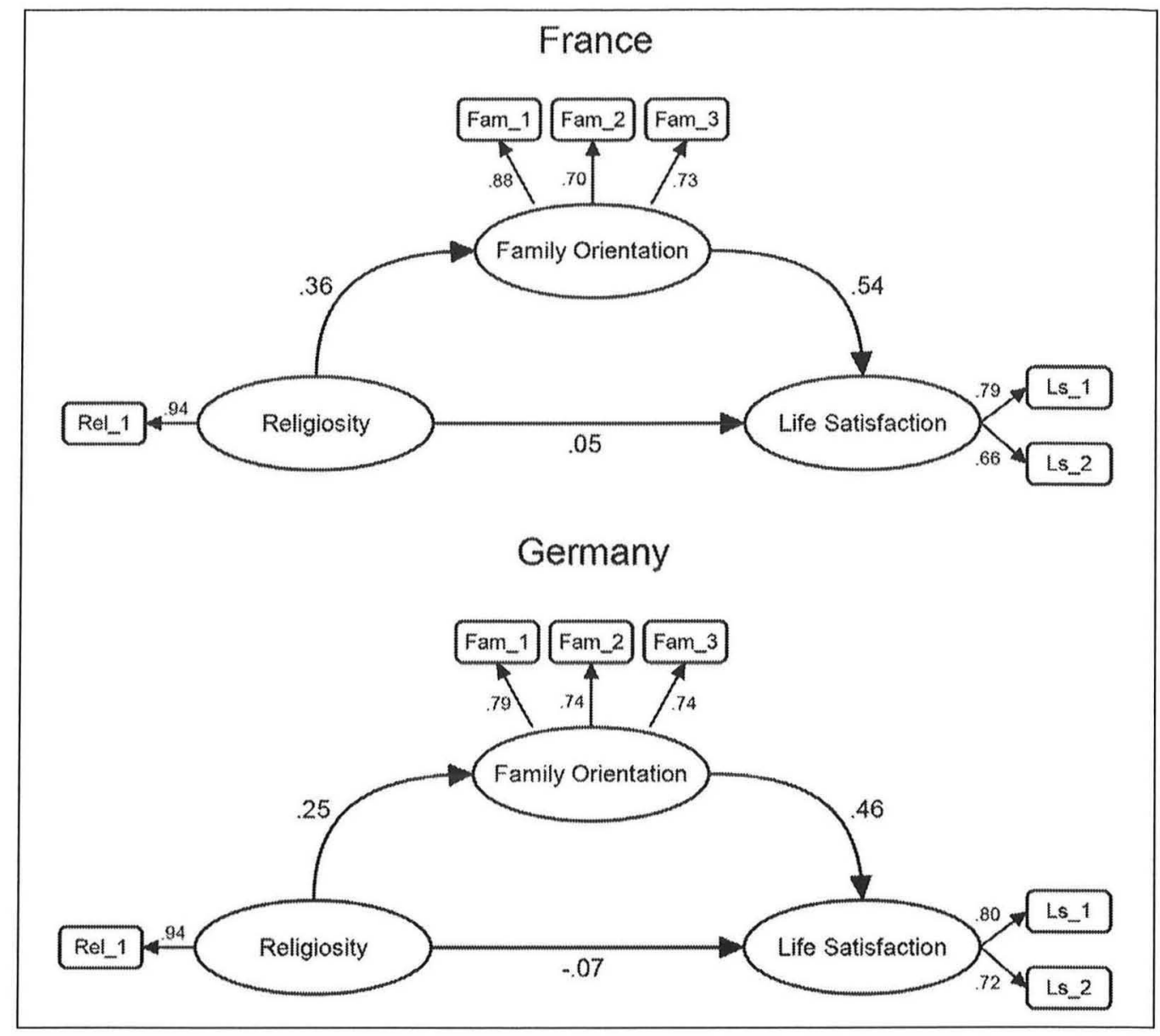

Figure 2a. Mediation Model for France and Germany

\section{Discussion}

The present study investigated the key role of family orientation as a connecting process between subjective religiosity and life satisfaction at adolescence. It was expected that the country religious contexts will moderate the links of the subjective religiosity with both life satisfaction and family orientation. In other words, it was expected that these links will be stronger in high religious countries than in secular countries.

The findings partially support our hypotheses. In all cultures, there was a positive indirect effect of adolescents' religiosity on their satisfaction with life via their family orientation and a nonsignificant direct effect. With regard to the moderation hypothesis, a significant overall effect (the combined effect of indirect and direct effects) of religiosity on life satisfaction occurred in all cultures, except for Germany. Similarly, the effect of religiosity on family orientation was significantly weaker in Germany as compared to Poland and the United States. Taken together, while in France, Poland, and the United States family orientation substantially mediated the effect of religiosity on life satisfaction, in Germany the indirect effect was weaker and no overall effect was observed. Simply put, our hypothesis concerning the mediation role of family 


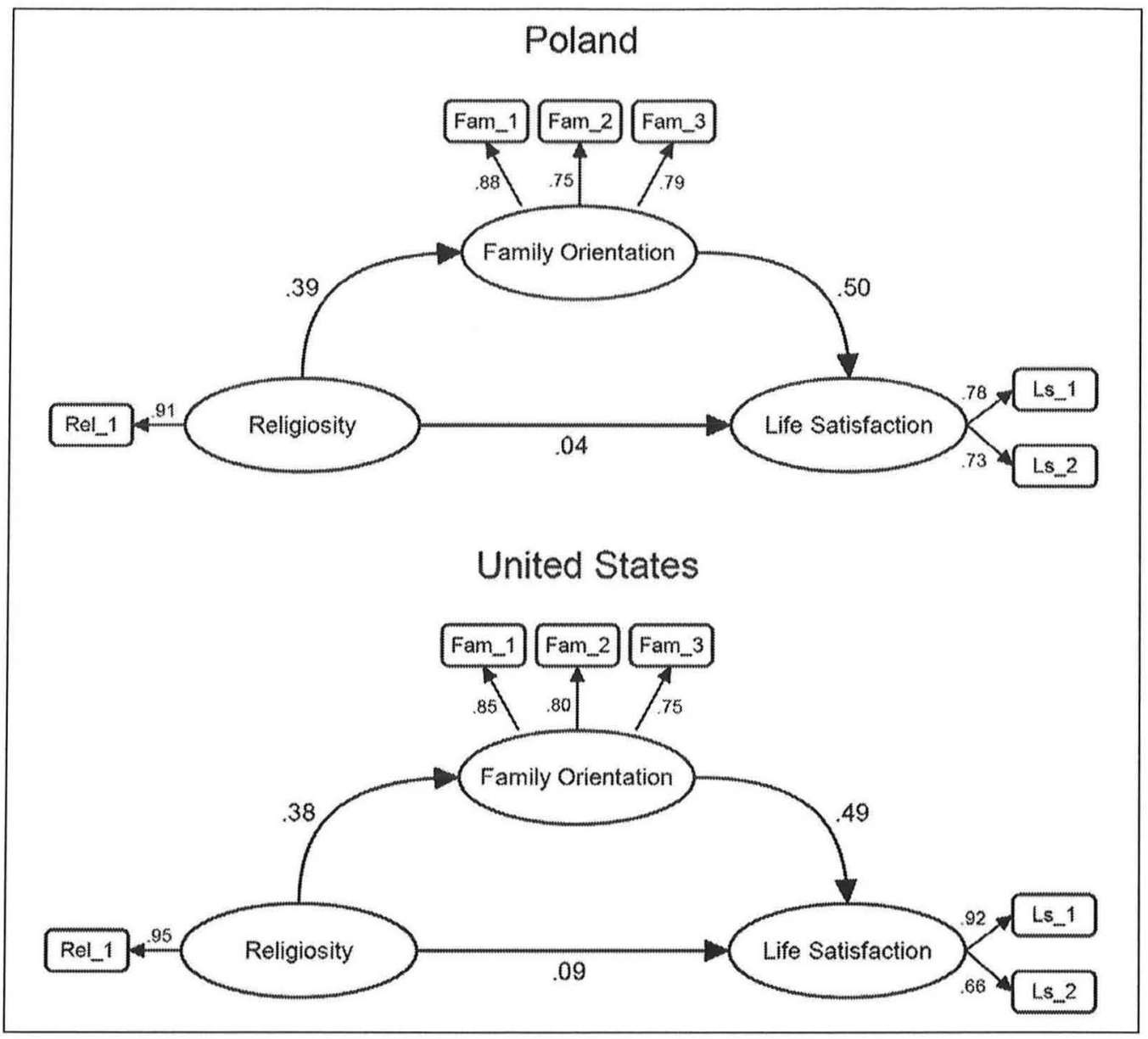

Figure 2b. Mediation Model for Poland and the United States

orientation between subjective religiosity and life satisfaction is supported in all cultures, and our hypotheses related to the religious context moderation of the links of religiosity and both family orientation and life satisfaction are only partially supported. These links were stronger in the two high religious countries (Poland and the United States) compared to Germany, one of the two secular countries, but the results in France lied in between.

In the present study, we have focused on the adolescent's personal endorsement of religiosity of adolescents and of family orientations instead of focusing on relationships with parents or on the effect of parents' religiosity (see Mahoney, 2010) or on the concordance between parents and adolescents with regard to religiosity (Flor \& Knapp, 2001). Family and religion are two institutions that are continuously changing. Since the middle of the 20th century, they have shifted from institutions emphasizing conformity toward a social unit of interacting personalities where adolescents have their say, in regard to family (Coontz, 2000), and toward a pursuit of personal faith and spirituality instead of a simple submission to dogmas or authorities, in regard to religiosity (Taylor, 2007). In such context, it is expected that adolescents built their own beliefs systems. Therefore, the internalization of religious beliefs and of family orientation rather than the submission to the parental values and beliefs is crucial (Good \& Willoughby, 2008; Silverstein \& 
Conroy, 2009). Our focus on adolescents' familial obligation and subjective religiosity is consonant with these transformations. Combined with our moderated mediation approach, it may represent an innovative contribution within the broad research field on religion and family with adolescents.

Furthermore, our findings reflect the relevance of the religious context of each country and the environmental affordance for family values and well-being. In Poland and the United States, to claim not to attribute importance to religious beliefs may not fit with the overall expectations of the society (Cieciuch, 2007; Kelley \& De Graaf, 1997). The difference between the adolescent and the social environment may accentuate the adolescents' strive for meaning and/or weaken their social connectedness and as a consequence may impede their satisfaction with life and their views on family solidarities (Kelley \& De Graaf, 1997; Regnerus \& Burdette, 2006). In France and in Germany, there is a long tradition as part of the heritage of the Enlightenment period of approaching individual well-being and family matter through a "secular lens." In these countries, religious and nonreligious adolescents benefit from many sources to maintain their well-being through a diversity of nonreligious programs. Subtle differences between France and Germany with regard to family policies and church-state historical relationships may explain our findings. France has a well-established state policy toward families (Revillard, 2007), and its history is embedded in the Catholic culture besides its tradition of strict church-state separation ("Eurel," 2010). In contrast, Germany has a loose government policy toward families and a historical tradition of balance between Protestant and Catholic faiths and views, which may have lowered the religious influence in secular concerns such as family policy.

Finally, this study leaves open many questions such as the generalization of the findings to other age groups (e.g., middle adulthood or old age) or the extension to other dimensions of wellbeing. Because adolescence is a turning point in the developmental course when family links are renegotiated and when values and religious beliefs are revisited, the internalization of family orientation may provide a sense of security for adolescents. It may be possible that our results are more characteristic for adolescents than for other age groups. Furthermore, according to Hackney and Sanders's (2003) categorization of dimensions of well-being, life satisfaction is one among several dimensions of well-being, besides the unhappy aspects of well-being (e.g., psychological distress, risk behaviors) and the growth-oriented and humanistic aspects, such as hope. Previous studies have shown that adolescent's religiosity is associated with hope and in general is more strongly associated with the positive aspects of well-being than with the negative ones (Markstrom, 1999; Wong et al., 2006). However, cross-cultural comparisons of the link between religiosity and other dimensions of well-being are scanty and none of these studies have examined the mediating role of family orientation, the focus of the present study.

\section{Limitations of the Study}

There are two main limitations of this study. First, although the results suggest that the relation between adolescents' religiosity and their life satisfaction is moderated by the level of religiosity of a given culture, it has to be emphasized that we were not able to rigorously test this assumption. For this, a multilevel analysis would be required that could not be applied with four cultures only. Second, our measure of religiosity based on a single question on the importance of religiosity is a very broad indicator (see Tarakeshwar, Stanton, \& Pargament, 2003, for a critical review). This simple question may overshadow a diversity of religious styles and does not inform about the cognitive style used to process religious content that in turn may influence the conceptions of family and the links between family orientation and well-being (Duriez, Soenens, Neyrinck, \& Vansteenkiste, 2009). 


\section{Conclusion}

The present research indicates that family orientation is relevant in explaining the link between religiosity and life satisfaction, among adolescents. During the period of renegotiation of values and relationships, religion contributes to the endorsement of family orientation and the internalization of family orientation may provide a sense of security and in consequence enhance life satisfaction. However, this link is more important in societies where family and religion are tightly linked than in societies with traditions to think about individual well-being and family matters through a "secular lens."

\section{Acknowledgments}

The project is part of the study "Value of Children and Intergenerational Relations" (Principal Investigators: Gisela Trommsdorff, University of Konstanz, and Bernhard Nauck, Technical University of Chemnitz) supported by a grant from the Deutsche Forschungsgemeinschaft (TR 169/9-1-3) to the last author. The first author is in debt to Amélie Sourdillat and Julie Sadaune for their preliminary work on the role of religiosity for family values and the well-being of adolescents in Catholic culture, as well as to Camille Brisset for her preliminary cross-cultural analyses and to the Laboratory of Research in psychology (Santé et qualité de vie, Victor Segalen) for its financial support in collecting and analyzing the data of the French sample.

\section{Declaration of Conflicting Interests}

The author(s) declared no potential conflicts of interest with respect to the research, authorship, and/or publication of this article.

\section{Funding}

The author(s) received no financial support for the research, authorship, and/or publication of this article.

\section{References}

Agate, S. T., Zabriskie, R. B., \& Eggett, D. L. (2007). Praying, playing and successful families: An examination of family religiosity, family leisure, and family functioning. Marriage \& Family Review, 42(2), 51-75.

Akaike, H. (1987). Factor analysis and AIC. Psychometrika, 52, 317-322.

Baron, R. M., \& Kenny, D. A. (1986). The moderator-mediator variable distinction in social psychological research: Conceptual, strategic and statistical considerations. Journal of Personality and Social Psychology, 51, 1173-1182.

Barrett, J. B., Pearson, J., Muller, C., \& Frank, K. A. (2007). Adolescent religiosity and school contexts. Social Science Quarterly, 88(4), 1024-1037.

Bengtson, V. L., \& Roberts, R. E. L. (1991). Intergenerational solidarity in aging families: An example of formal theory construction. Journal of Marriage \& Family, 53(4), 856-870.

Berne, L. A., \& Huberman, B. K. (2000). Lessons learned: European approaches to adolescent sexual behavior and responsibility. Journal of Sex Education \& Therapy, 25(2), 189-199.

Boski, P. (2009). Kulturowe ramy zachowań spolecznych. Podręcznik psychologii miedzykulturowej [Cultural framework of social behavior. Handbook of intercultural psychology]. Warszawa, Poland: PWN.

Bourdieu, P. (1980). Le capital social. Actes de la Recherche en Sciences Sociales, 31, 2.

Caprara, G. V., Pastorelli, C., Regalia, C., Scabini, E., \& Bandura, A. (2005). Impact of adolescents' filial self-efficacy on quality of family functioning and satisfaction. Journal of Research on Adolescence, 15(1), 71-97.

Casas, F., Figuer, C., Gonzalez, M. N., \& Malo, S. (2007). The values adolescents aspire to, their well-being and the values parents aspire to for their children. Social Indicators Research, 84(3), 271-290. 
Chatters, L. M., \& Taylor, R. J. (2005). Religion and families. In V. L. Bengtson, A. C. Acock, K. R. Allen, P. Dilworth-Anderson, \& D. M. Klein (Eds.), Sourcebook of family theory \& research (pp. 517-541). Thousand Oaks, CA: Sage.

Cieciuch, J. (2007). Family - Fatherland - God in the value system of Polish adolescents. Polish Psychological Bulletin, 38(4), 181-188.

Cohen, A. B. (2002). The importance of spirituality in well-being for Jews and Christians. Journal of Happiness Studies, 3(3), 287-310.

Cohen, A. B., Pierce, J. D., Jr., Chambers, J., Meade, R., Gorvine, B. J., \& Koenig, H. G. (2005). Intrinsic and extrinsic religiosity, belief in the afterlife, death anxiety, and life satisfaction in young Catholics and Protestants. Journal of Research in Personality, 39(3), 307-324.

Coontz, S. (2000). Historical perspectives on family studies. Journal of Marriage \& the Family, 62(2), 283-297.

Cross, S. E., Bacon, P. L., \& Morris, M. L. (2000). The relational-interdependent self-construal and relationships. Journal of Personality and Social Psychology, 78(4), 791-808.

Day, R. D., Jones-Sanpei, H., Smith Price, J. L., Orthner, D. K., Hair, E. C., Moore, K. A., et al. (2009). Family processes and adolescent religiosity and religious practice: View from the NLSY97. Marriage \& Family Review, 45(2/3), 289-309.

Diener, E., Gohm, C. L., Suh, E., \& Oishi, S. (2000). Similarity of the relations between marital status and subjective well-being across cultures. Journal of Cross-Cultural Psychology, 31(4), 419-436.

Diener, E., Suh, E., Lucas, R. E., \& Smith, H. (1999). Subjective well-being: Three decades of progress. Psychological Bulletin, 125, 276-302.

Duriez, B., Soenens, B., Neyrinck, B., \& Vansteenkiste, M. (2009). Is religiosity related to better parenting? Disentangling religiosity from religious cognitive style. Journal of Family Issues, 30(9), 1287-1307.

Erikson, E. (1968). Identity, youth and crisis. New York: Norton and Co.

"Eurel." (2010, March 3). Retrieved from http://www.eurel.info/

Ferriss, A. L. (2002). Religion and the quality of life. Journal of Happiness Studies, 3(3), 199-215.

Flor, D. L., \& Knapp, N. F. (2001). Transmission and transaction: Predicting adolescents' internalization of parental religious values. Journal of Family Psychology, 15(4), 627-645.

Francis, L. J., Jones, S. H., \& Wilcox, C. (2000). Religiosity and happiness: During adolescence, young adulthood, and later life. Journal of Psychology and Christianity, 19(3), 245-257.

Francis, L. J., Ziebertz, H.- G., \& Lewis, C. A. (2003). The relationship between religion and happiness among German students. Pastoral Psychology, 51(4), 273-281.

Geertz, C. (1973). Religion as a cultural system. In C. Geertz (Ed.), The interpretation of cultures (pp. 87-125). New York: Basic Books.

Georgas, J., Berry, J. W., van de Vijver, F. J. R., Kagitçibasi, C., \& Poortinga, Y. H. (2006). Families across cultures: A 30-nation psychological study. New York: Cambridge University Press.

Good, M., \& Willoughby, T. (2008). Adolescence as a sensitive period for spiritual development. Child Development Perspectives, 2(1), 32-37.

Hackney, C. H., \& Sanders, G. S. (2003). Religiosity and mental health: A meta-analysis of recent studies. Journal for the Scientific Study of Religion, 42(1), 43-55.

Hayduk, L. A. (1996). LISREL: Issues, debates, and strategies. Baltimore: The Johns Hopkins University Press.

Henrich, G. E., \& Herschbach, P. (1995). Fragen zur lebenszufriedenheit (FLZ)—Ein gewichtungsmodell [Questions on life satisfaction. A weighting model]. In R. Schwarz, J. Bernhard, H. Flechtner, T. Küchler, \& C. Hürny (Eds.), Lebensqualität in der onkologie (pp. 77-93). München, Germany: Zuckerschwerdt Verlag.

Huebner, E. S. (2004). Research on assessment of life satisfaction of children and adolescents. Social Indicators Research, 66(1-2), 3-33.

Human Development Report. (2009). Retrieved from http://hdr.undp.org/en/humandev/ 
Kagitçibasi, C. (2007). Family, self, and human development across cultures. Theory and applications (2nd ed.). Mahwah, NJ: Erlbaum.

Kelley, J., \& De Graaf, N. D. (1997). National context, parental socialization, and religious belief: Results from 15 nations. American Sociological Review, 62(4), 639-659.

Kenny, D. A. (2009). Mediation. Retrieved July 15, 2010, from http://davidakenny.net $/ \mathrm{cm} / \mathrm{mediate}$.htm

King, E. P., \& Furrow, J. L. (2004). Religion as a resource for positive youth development: Religion, social capital, and moral outcomes. Developmental Psychology, 40(5), 703-713.

Lavric, M., \& Flere, S. (2008). The role of culture in the relationship between religiosity and psychological well-being. Journal of Religion \& Health, 47(2), 164-175.

Little, T. D., Cunningham, W. A., Shahar, G., \& Widaman, K. F. (2002). To parcel or not to parcel: Exploring the question, weighing the merits. Structural Equation Modeling, 9(2), 151-173.

Mahoney, A. (2005). Religion and conflict in marital and parent-child relationships. Journal of Social Issues, 61(4), 689-706.

Mahoney, A. (2010). Religion in families, 1999-2009: A relational spirituality framework. Journal of Marriage \& Family, 72(4), 805-827.

Markstrom, C. A. (1999). Religious involvement and adolescent psychosocial development. Journal of Adolescence, 22(2), 205-221.

Okulicz-Kozaryn, A. (2010). Religiosity and life satisfaction (A multilevel investigation across nations). Mental Health, Religion \& Culture, 13(2), 155-169.

Pew Research Center. (2002). Among wealthy nations US stands alone in its embrace of religion. Reports. Retrieved from http://people-press.org/

Pomerantz, E. M., Qin, L., Wang, Q., \& Chen, H. (2009). American and Chinese early adolescents' inclusion of their relationships with their parents in their self-construals. Child Development, 80(3), 792-807.

Proctor, C. L., Linley, P. A., \& Maltby, J. (2009). Youth life satisfaction: A review of the literature. Journal of Happiness Studies, 10(5), 583-630.

Regnerus, M. D., \& Burdette, A. (2006). Religious change and adolescent family dynamics. The Sociological Quarterly, 47(1), 175-194.

Regnerus, M. D., Smith, C., \& Smith, B. (2004). Social context in the development of adolescent religiosity. Applied Developmental Science, 8(1), 27-38.

Revillard, A. (2007). Stating family values and women's rights: Familialism and feminism within the French Republic. French Politics, 5, 210-228.

Roccas, S., \& Schwartz, S. H. (1997). Church-state relations and the association of religiosity with values: A study of Catholics in six countries. Cross-Cultural Research: The Journal of Comparative Social Science, 31(4), 356-375.

Saroglou, V., Delpierre, V., \& Dernelle, R. (2004). Values and religiosity: A meta-analysis of studies using Schwartz's model. Personality and Individual Differences, 37(4), 721-734.

Saroglou, V., \& Munoz-Garcia, A. (2008). Individual differences in religion and spirituality: An issue of personality traits and/or values. Journal for the Scientific Study of Religion, 47(1), 83-101.

Silverstein, M., \& Conroy, S. J. (2009). Intergenerational transmission of moral capital across the family life course. In U. Schönpflug (Ed.), Cultural transmission: Psychological, developmental, social, and methodological aspects (pp. 317-337). New York: Cambridge University Press.

Singelis, T. M. (1994). The measurement of independent and interdependent self-construals. Personality and Social Psychology Bulletin, 20(5), 580-591.

Snider, J. B., Clements, A., \& Vazsonyi, A. T. (2004). Late adolescent perceptions of parent religiosity and parenting processes. Family Process, 43(4), 489-502.

Steger, M. F., \& Frazier, P. (2005). Meaning in life: One link in the chain from religiousness to well-being. Journal of Counseling Psychology, 52(4), 574-582.

Sweeting, H., \& West, P. (1995). Family life and health in adolescence: A role for culture in the health inequalities debate. Social Science \& Medicine, 40(2), 163-175. 
Tarakeshwar, N., Stanton, J., \& Pargament, K. I. (2003). Religion: An overlooked dimension in crosscultural psychology. Journal of Cross-Cultural Psychology, 34(4), 377-394.

Taylor, C. (2007). A secular age. Cambridge, MA: The Belknap Press of Harvard University Press.

Trommsdorff, G., \& Nauck, B. (2005). The value of children in cross-cultural perspective. Case studies from eight societies. Lengerich, Germany: Pabst Science Publishers.

Valenzuela, A., \& Dornbusch, S. M. (1994). Familism and social capital in the academic achievement of Mexican origin and Anglo adolescents. Social Science Quarterly, 75(1), 18-36.

van de Vijver, F. J. R., \& Leung, K. (1997). Methods and data analysis for cross-cultural research. Thousand Oaks, CA: Sage.

Vedder, P., Berry, J. W., Sabatier, C., \& Sam, D. L. (2009). The intergenerational transmission of values in national and immigrant families: The role of zeitgeist. Journal of Youth and Adolescence, 38, 642-653.

Wong, Y. J., Rew, L., \& Slaikeu, K. D. (2006). A systematic review of recent research on adolescent religiosity/spirituality and mental health. Issues in Mental Health Nursing, 27(2), 161-183. 